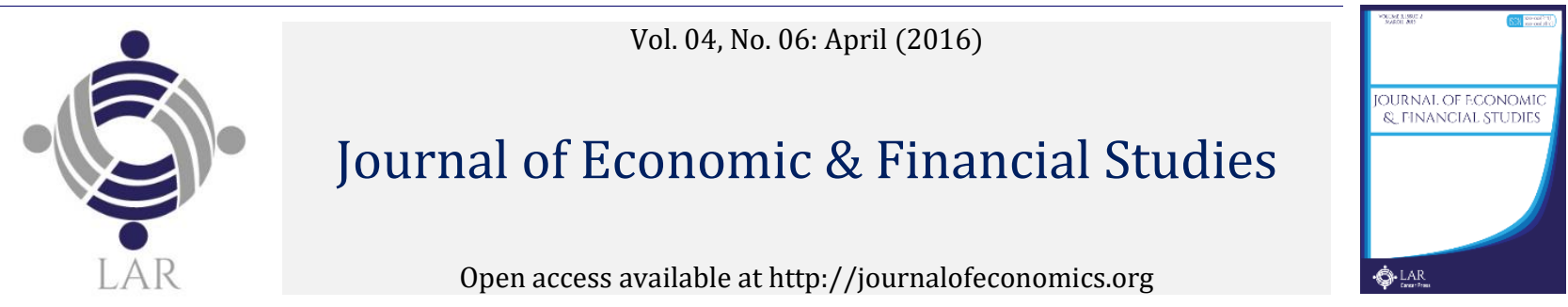

\title{
Properties of the Financial Break-Even Point in a Simple Investment Project As a Function of the Discount Rate
}

\author{
Domingo Alberto Tarzia $\mathrm{a}^{*}$ \\ a Depto. Matemática - CONICET, FCE, Univ. Austral, Paraguay 1950, S2000FZF Rosario, Argentina. \\ *Corresponding author's email address: DTarzia@austral.edu.ar
}

\section{A R T I C L E I N F O}

Received: 16-03-2016

Accepted: 27-04-2016

Available online: 05-05-2015

Keywords:

Financial break-even point; Investment project:

Net present value;

Discount rate;

Accounting break-even point;

Asymptotic behavior;

Sensitivity analysis.

JEL Classification :

C02; C63; G10; G31.

A B S T R A C T

We consider a simple investment project with the following parameters: I $>0$ : Initial outlay which is amortizable in $n$ years; $n$ : Number of years the investment allows production with constant output per year; $\mathrm{A}>0$ : Annual amortization $(A=I / n) ; Q>0$ : Quantity of products sold per year; $\mathrm{C}_{\mathrm{v}}>0$ : Variable cost per unit; $\mathrm{p}>0$; Price of the product with $\mathrm{P}>\mathrm{C}_{\mathrm{v}} ; \mathrm{C}_{\mathrm{f}}>0$ : Annual fixed costs; te: Tax of earnings; $r$ : Annual discount rate. We also assume inflation is negligible. We derive a closed expression of the financial break-even point $Q_{f}$ (i.e. the value of $\mathrm{Q}$ for which the net present value (NPV) of the investment project is zero) as a function of the parameters $I, n, C_{v}, C_{f}, t_{e}, r, p$. We study the behavior of $Q_{f}$ as a function of the discount rate $r$ and we prove that: (i) For $r$ negligible $\mathrm{Q}_{\mathrm{f}}$ equals the accounting break-even point $\mathrm{Q}_{\mathrm{c}}$ (i.e. the earnings before taxes (EBT) is null); (ii) When $r$ is large the graph of the function $\mathrm{Q}_{\mathrm{f}}=\mathrm{Q}_{\mathrm{f}}(\mathrm{r})$ has an asymptotic straight line with positive slope. Moreover, $\mathrm{Q}_{\mathrm{f}(\mathrm{r})}$ is an strictly increasing and convex function of the variable $r$; (iii) From a sensitivity analysis we conclude that, while the influence of $p$ and $C_{V}$ on $Q_{f}$ is strong, the influence of $C_{f}$ on $Q_{f}$ is weak; (iv) Moreover, if we assume that the output grows at the annual rate $g$ the previous results still hold, and, of course, the graph of the function $Q_{f}=Q_{f}(r, g)$ vs $r$ has, for all $g>0$ the same asymptotic straight line when $r$ trends to infinite as in the particular case with $g=0$. From our point of view, a result of this type is the first time which is obtained by a simple investment project being the cornerstone of our proof the explicit expression of the net present value and the corresponding financial break-even point value. A policy implication of our findings is that the results can be taken into account for investment projects, especially in countries with very small or very large discount rates.
\end{abstract}

(C) 2016 The Authors. This is an open access article under the terms of the Creative Commons Attribution License 4.0, which allows use, distribution and reproduction in any medium, provided the original work is properly cited.

DOI: http://dx.doi.org/10.18533/jefs.v4i02.226

\section{$1.0 \quad$ Introduction}

A rigorous evaluation of an investment project is crucial for the evaluation of its convenience, see the books (Alhabeeh, 2012; Bierman and Smidt, 1993; Bodmer, 2015; Brealey and Myers, 1993; De Pablo, Ferruz and Santamaria, 1990; Lopez Dumrauf, 2003; Suarez Suarez, 1991). Among the different methods to evaluate investment project we choose the net present value (NPV) (Baker and Fox, 2003; Beaves, 1988; Bric and Weaver, 1997; Chung and Lin, 1998; Grinyer and Walker, 1990; Hadjdasinski 1993, 1995, 1996, 1997; Hartman and Schafrick, 2004; Hazen, 2003; Kim and Chung, 1990; Lan, Chung, Chu and Kuo, 2003; Lohmann, 1994; Lohmann and Baksh, 1993; Moon and Yun, 1993; Pasin and Leblanc, 1996; Pierru and Feuillet Midrier, 2002; Prakash, Dandapani and Karels, 1988; Reichelstein, 2000; Roumi and Schnabel, 1990; Shull, 1992; Stanford, 1989; and Zhang 2005). Assuming the absence of inflation we consider a simple investment project with the following parameters: 
$I>0$ : Initial outlay which is amortizable in $n$ years;

$n>1$ : Numbers of years of the explicit forecasted period of the investment project which make the same activities per year with only one product;

$Q>0$ : Quantity of products sold per year;

$C_{v}>0$ : Variable cost per unit;

$p>0$ : Price per unit with $p>C_{v}$;

$C_{f}>0$ : Annual fixed costs;

$t>0$ : Time;

$t_{e}>0$ : Tax of earnings (legal tax rate);

$r>0$ : Annual discount rate;

$g>0$ : Annual growth rate.

Moreover, we also consider the annual amortization $(A=I / n>0)$ which depends of two parameters $I$ and $n$

In Fernandez Blanco (1991) a first study for the $N P V$ of an investment project was done, and we complete and improve it. There exist several papers on $N P V$ but, from our point of view, we have not found in the literature a study of the mathematical-financial properties of the financial break-even point and this is the main objective of the present paper. We derive first an explicit expression of the $N P V$ as a function of the independent variable $Q$ in order to obtain a closed formula of the financial break-even point $Q_{f}$ (the value of $Q$ for which the $N P V$ of the investment project is zero) as a function of the parameters $\left(I, n, C_{v}, C_{p}, t_{e}, r, p\right)$.

Recent applications of the net present value and the break-even analysis can be found: break-even point between short-term and long-term capital gain (loss) strategies, (Yang and Meziani, 2012); break-even procedure for a multi-period project, (Kim and Kim, 1996); to mazimize the net present value of projects, (Schwindt and Zimmermann, 2001; Vanhoucke, Demeulemeester and Herroelen, 2001a,b); the internal rate of return as a financial indicator, (Hajdasinski, 2004); private competitiveness, production costs and break-even analysis of representative production units, (Martinez Medina et al., 2015); the net present value as an optimal criterium of investing, (Machain, 2002); break-even points for storage systems as a substitute to conventional grid reinforcements, (Nykamp et al. 2014); to measure and analyse the operating risk, financial risk, financial break-even point and total risk of a selected public sector, (Sarkar and Sarkar, 2013); risk diagnosis in the context of economic crisis, (Suciu, 2010); marginal break-even between maintenance strategies alternatives, (Gokiene, 2010); relationship among discount cash flow, free cash flow, economic value added and net present value, (Hartman, 2000; Shieres and Wachowicz, 2001); running a profitable company, (Paek, 2000).

The break-even analysis is a useful tool to study the relationship among fix costs, variable costs and returns. The break-even analysis computes the volume of production at a given price necessary to cover all costs. The economical-financial literature on the financial break-even point of an investment project is scarce, and then we would like to provide the clear understanding on the behavior of its financial break-even point value as a function of the discount rate; from our point of view, a result of this type is the first time which is obtained for an investment project, and it is particularly important in countries with very small or very large discount rates.

We study the behavior of $Q_{f}=Q_{f}(r)$ with respect of the discount rate $r$, and we obtain the following results:

(i) When $r$ is negligible ( $r$ goes to zero) then $Q_{f}$ tends to the accounting break-even point $Q_{c}$ (the value of $Q$ for which the earnings before taxes (EBT) of the investment project is equals to zero) (see Section 2);

(ii) When $r$ is large ( $r$ goes to infinity) the graph of the function $Q_{f}=Q_{f}(r)$ has an asymptotic straight line. Its positive slope and the y-intercept point at $r=0$ are determined explicitly. Moreover, $Q_{f}(r)$ is an strictly increasing and convex function of the variable $r$ (see Section 2);

(iii) By a sensitivity analysis we obtain that $p$ and $C_{v}$ have an important influence on $Q_{f}$, but $C_{f}$ has a negligible influence on $Q_{f}$ (see Section 3); 
(iv) Moreover, if we assume that the output grows at the annual rate $g$ the previous results still hold and, of course, the graph of the function $Q_{f}=Q_{f}(r, g) v s r$ has, for all $g>0$, the same asymptotic straight line when $r \rightarrow \infty$ as in the particular case with $g=0$ (see Section 4 ).

\subsection{Investment project with the independent variable $\mathbf{Q}$}

We assume that in each year $(t=1,2, \ldots, n)$ the company do the same activities, i.e. the parameters $Q, p, C_{f}$, $C_{v}, r, t_{e}$ are constants during the $n$ years of the investment project. For each year $t(t=1,2, \ldots, n)$ the net cash flow is given by:

$$
\begin{aligned}
F & =\left(1-t_{e}\right)\left[\left(p-C_{v}\right) Q-C_{f}-A\right]+A \\
& =\left(1-t_{e}\right)\left[\left(p-C_{v}\right) Q-C_{f}\right]-\left(1-t_{e}\right) A+A \\
& =\left(1-t_{e}\right)\left[\left(p-C_{v}\right) Q-C_{f}\right]+t_{e} A,
\end{aligned}
$$

and then, by using the calculation of the sum of the first $\mathrm{n}$ terms of a geometric sequence, the $N P V$ of the investment project is given by (Brealey and Myers, 1993; Sapag Chain, 2001; Tang and Tang, 2003; Villalobos, 2001):

$$
\begin{gathered}
N P V(Q)=-I+\sum_{t=1}^{n} \frac{F}{(1+r)^{t}}=-I+F \frac{1}{r}\left[1-\frac{1}{(1+r)^{n}}\right] \\
=-I+\frac{1}{r}\left[1-\frac{1}{(1+r)^{n}}\right]\left[\left(1-t_{e}\right)\left(p-C_{v}\right) Q-\left(1-t_{e}\right) C_{f}+t_{e} A\right]=h+m Q
\end{gathered}
$$

which represents a straight line of the variable $Q$ with

$$
\begin{gathered}
h=h(r)=-I+f(r)\left[t_{e} A-\left(1-t_{e}\right) C_{f}\right] \text { (y-intercept of the straight line), } \\
m=m(r)=f(r)\left(p-C_{v}\right)\left(1-t_{e}\right)>0 \text { (slope of the straight line), }
\end{gathered}
$$

where the real function $f=f(r)$ is defined by the following expression:

$$
f(r)=\frac{1}{r}\left[1-\frac{1}{(1+r)^{n}}\right], \quad r>0 \text {. }
$$

Taking into account that the financial break-even $Q_{f}$ is defined as the value of $Q$ which satisfies $N P V(Q)=0$ , we obtain that

$$
N P V\left(Q_{f}\right)=0 \Leftrightarrow h(r)+m(r) Q_{f}=0,
$$

that is,

$$
Q_{f}=Q_{f}(r)=\left\{\left(1-t_{e}\right) C_{f}-t_{e} A+\frac{I}{f(r)}\right\} \frac{1}{\left(p-C_{v}\right)\left(1-t_{e}\right)}=-\frac{h(r)}{m(r)},
$$

and therefore the financial break-even point $Q_{f}$, as a function of the discount rate $r$, is given by the following expression:

$Q_{f}(r)=a+b \frac{1}{f(r)}$,

where the real coefficients $a$ and $b$ are given by

$$
a=a=\frac{C_{f}-t_{e}\left(C_{f}+A\right)}{\left(p-C_{v}\right)\left(1-t_{e}\right)}
$$


$b=\frac{I}{\left(p-C_{v}\right)\left(1-t_{e}\right)}>0$.

Taking into account the formula (6) of the financial break-even point $Q_{f}$ the formula (7) of the net present value $N P V(Q)=N P V(Q, r)$ has an equivalent expression given by

$N P V(Q, r)=-I+f(r)\left[t_{e} A-\left(1-t_{e}\right) C_{f}\right]+f(r)\left(p-C_{v}\right)\left(1-t_{e}\right) Q$.

or equivalently by

$$
N P V(Q, r)=m(r)\left[Q-Q_{f}(r)\right] \text {. }
$$

Thus we have obtained an expression of the $N P V$ as a function of the variable $Q$, the discount rate $r$, and the financial break-even point $Q_{f}(r)$. The previous result can be summarized as follows.

\section{Theorem 1}

The investment project has the following properties:

(i) The $N P V$, as a function of the units sold per year $Q$, is given by (1) where the y-intercept $h$ and the slope $m$ are expressed by (2) and (3) respectively where $f=f(r)$ is the real function defined by (4).

(ii) The financial break-even point $Q_{f}$, as a function of the discount rate $r$, is given by

$Q_{f}(r)=a+b F(r)$,

where the real function $F=F(r)$ is defined by

$$
F(r)=\frac{1}{f(r)}=\frac{r}{1-\frac{1}{(1+r)^{n}}}, \quad r>0 \text {, }
$$

and the coefficients $a$ and $b$ are given by the expressions (8) and (9) respectively.

(iii) The $N P V(Q, r)$ can also be calculated as a function of the $Q_{f}$ by the expression (11).

(iv) The sign of the $\operatorname{NPV}(Q, r)$, as a function of the financial break-even point $Q_{f}(r)$, is given by

$$
N P V(Q, r)\left\{\begin{array}{l}
>0 \Leftrightarrow Q>Q_{f}(r) \\
=0 \Leftrightarrow Q=Q_{f}(r) \\
<0 \Leftrightarrow 0 \leq Q<Q_{f}(r) .
\end{array}\right.
$$

In order to analyse the matematical behavior of the function $N P V=N P V(Q, r)$ and the financial break-even point $Q_{f}=Q_{f}(r)$ we need to study the behavior of the real functions $f=f(r)$ and $F=F(r)$ defined by (4) and (13) respectively which have the following properties.

\section{Theorem 2}

(i) The function $f=f(r)$ is a strictly decreasing and convex function of the discount rate $r$ with the following properties:

$$
\begin{aligned}
& f\left(0^{+}\right)=\lim _{r \rightarrow 0^{+}} f(r)=n>0, f(+\infty)=\lim _{r \rightarrow+\infty} f(r)=0, \\
& \frac{d f(r)}{d r}=f^{\prime}(r)=-\frac{G(r)}{r^{2}(1+r)^{n+1}}<0, \forall r>0, \\
& f^{\prime}\left(0^{+}\right)=\lim _{r \rightarrow 0^{+}} f^{\prime}(r)=-\frac{n(n+1)}{2}, f^{\prime}(+\infty)=\lim _{r \rightarrow+\infty} f^{\prime}(r)=0,
\end{aligned}
$$


$f^{\prime \prime}(r)=\frac{H(r)}{r^{3}(1+r)^{n+2}}>0, \forall r>0$,

$f^{\prime \prime}\left(0^{+}\right)=\lim _{r \rightarrow 0^{+}} f^{\prime \prime}(r)=\frac{n(n+1)(n+2)}{3}, f^{\prime \prime}(+\infty)==\lim _{r \rightarrow+\infty} f^{\prime \prime}(r)=0$,

where the real functions $G=G(r)$ and $H=H(r)$ are defined by

$G(r)=(1+r)^{n+1}-1-(n+1) r, r>0$,

$H(r)=2(1+r)^{n+2}-2-2(n+2) r-(n+1)(n+2) r^{2}, r>0$,

which have the following properties:

$G\left(0^{+}\right)=\lim _{r \rightarrow 0^{+}} G(r)=0, G(+\infty)=\lim _{r \rightarrow+\infty} G(r)=+\infty, G(r)>0, \forall r>0$,

$H\left(0^{+}\right)=\lim _{r \rightarrow 0^{+}} H(r)=0, H(+\infty)=\lim _{r \rightarrow+\infty} H(r)=+\infty, H(r)>0, \forall r>0$.

(ii) The real function $F=F(r)$, defined in (13), is a strictly increasing function and has at $r=+\infty$ an asymptotic straight line given by the equation $y=r$ (straight line with slope 1 and y-intercept 0 ) and the following properties:

$F\left(0^{+}\right)=\lim _{r \rightarrow 0^{+}} F(r)=\frac{1}{n}, F(+\infty)=\lim _{r \rightarrow+\infty} F(r)=+\infty$,

$\frac{1}{2}<F^{\prime}\left(0^{+}\right)=\lim _{r \rightarrow 0^{+}} F^{\prime}(r)=\frac{1}{2}\left(1+\frac{1}{n}\right)<1, \quad \forall n>1$,

$F^{\prime \prime}\left(0^{+}\right)=\lim _{r \rightarrow 0^{+}} F^{\prime \prime}(r)=\frac{n^{2}-1}{6 n}$,

$0<F(r)-r<\frac{1}{n}, \quad \forall r>0, \quad \forall n>1$.

\section{Proof.}

All properties of the real functions $f, F, G$ and $H$ can be proved by using elementary mathematical analysis (derivatives, l'Hopital rule, increasing and convexity of functions, asymptotic straight lines, etc.).

Taking into account that the earnings before taxes $(E B T)$ is calculated by

$$
E B T=p Q-C_{v} Q-C_{f}-A=\left(p-C_{v}\right) Q-C_{f}-A,
$$

and defining the accounting break-even point $Q_{c}$ as the value $Q$ for which the $E B T$ is zero then $Q_{c}$ is given by the following expression

$$
\operatorname{BAT}\left(Q_{c}\right)=0 \Leftrightarrow\left(p-C_{v}\right) Q_{c}-C_{f}-A=0 \Leftrightarrow
$$

$Q_{c}=\frac{C_{f}+A}{p-C_{v}}$.

\section{Theorem 3}

The financial break-even point $Q_{f}=Q_{f}(r)$, given by (12), is a strictly increasing function of the discount rate $r$ and has the following properties:

$Q_{f}\left(0^{+}\right)=\lim _{r \rightarrow 0^{+}} Q_{f}(r)=a+\frac{b}{n}=Q_{c}, Q_{f}(+\infty)=\lim _{r \rightarrow+\infty} Q_{f}(r)=+\infty$, 


$$
\begin{aligned}
& \frac{d Q_{f}(r)}{d r}>0, \forall r>0, \\
& 0<\frac{b}{2}<\frac{d Q_{f}\left(0^{+}\right)}{d r}=\lim _{r \rightarrow 0^{+}} \frac{d Q_{f}}{d r}(r)=\frac{b}{2}\left(1+\frac{1}{n}\right)<b .
\end{aligned}
$$

Moreover, the function $y=Q_{f}(r)$ has at $r=+\infty$ a straight line given by the equation

$$
y=a+b r
$$

which has a slope $b>0$ and y-intercept $a$, defined in (9) and (8) respectively.

\section{Proof}

Taking into account the properties of the functions $f=f(r)$ and $F=F(r)$, obtained in Theorem 2, we have the following results:

$Q_{f}\left(0^{+}\right)=\lim _{r \rightarrow 0^{+}} Q_{f}(r)=a+b \lim _{r \rightarrow 0^{+}} F(r)=a+b F\left(0^{+}\right)=a+\frac{b}{n}=\frac{C_{f}+A}{p-C_{v}}=Q_{c}$

which is the accounting break-even point $Q_{c}$ defined by (28). On the other words, we have the following properties:

$$
\begin{aligned}
& Q_{f}(+\infty)==\lim _{r \rightarrow+\infty} Q_{f}(r)=a+b \lim _{r \rightarrow+\infty} F(r)=a+b F(+\infty)=+\infty, \\
& \frac{d Q_{f}}{d r}(r)=b F^{\prime}(r)>0, \forall r>0, \\
& \frac{b}{2}<\frac{d Q_{f}}{d r}\left(0^{+}\right)=b F^{\prime}(0)=\frac{b}{2}\left(1+\frac{1}{n}\right)<b, \forall n>1 .
\end{aligned}
$$

Moreover, the function $y=F(r)$ for $r=+\infty$ becomes asymptotic to the straight line whose equation is given by the equation $y=r$, and then the function $y=Q_{f}(r)$ for $r=+\infty$ is asymptotic to the straight line $y=a+b r$ because

$$
\text { i) } \lim _{r \rightarrow+\infty} \frac{Q_{f}(r)}{r}=\lim _{r \rightarrow+\infty} \frac{a+b F(r)}{r}=b \lim _{r \rightarrow+\infty} \frac{F(r)}{r}=b \text {, }
$$

ii) $\lim _{r \rightarrow+\infty}\left[Q_{f}(r)-b r\right]=\lim _{r \rightarrow+\infty}[a+b F(r)-b r]=a+b \lim _{r \rightarrow+\infty}(F(r)-r)=a$.

\section{Remark 1}

The limit (33) has an interesting accounting-financial property: the limit of the financial break-even point $Q_{f}=Q_{f}(r)$ when the discount rate goes to zero (i.e., discount rate is negligible) is equal to the accounting breakeven point $Q_{c}$.

\section{Remark 2}

The financial break-even point of the investnment project, as a function of the discount rate $r$, is given by a strictly increasing and convex function $y=Q_{f}(r)$ which at $r=0$ has the value $Q_{f}\left(0^{+}\right)=a+b / n=Q_{c}$ (accounting break-even point) and for $r=+\infty$ tends asymptotically to the straight line of equation $y=a+b r$ where $a$ and $b$ are defined in (8) and (9) respectively. On the other hand, the curve $y=Q_{f}(r)$ has an initial slope $Q_{f}{ }^{\prime}\left(0^{+}\right)$ at $r=0$ which has a value between $b / 2$ and $b$, less than the slope $b$ of the asymptote for $r=+\infty$. 
Taking into account the result (29) an interesting question is to determine the rate of convergence of the financial break-even point $Q_{f}=Q_{f}(r)$ to the accounting break-even point $Q_{c}$ when the discount rate $r$ goes to zero.

\section{Lemma 4}

We have

$0<Q_{f}(r)-Q_{c}=\frac{I}{\left(p-C_{v}\right)\left(1-t_{e}\right)}\left(F(r)-\frac{1}{n}\right), \quad \forall r>0$,

and the rate of convergence is of order one and it is given by

$0<Q_{f}(r)-Q_{c} \approx \frac{I}{2\left(p-C_{v}\right)\left(1-t_{e}\right)}\left(1+\frac{1}{n}\right) r, \quad$ as $r \rightarrow 0$.

Proof

Taking into account formulas (7) or (12) for $Q_{f}(r)$, and formula (28) for $Q_{c}$, we obtain:

$Q_{f}(r)-Q_{c}=\frac{C_{f}-t_{e}\left(C_{f}+A\right)+I F(r)}{\left(p-C_{v}\right)\left(1-t_{e}\right)}-\frac{I F(r)-A}{p-C_{v}}=\frac{I F(r)-A}{\left(p-C_{v}\right)\left(1-t_{e}\right)}$,

that is (38). Now, taking into account the properties (24) and (25) for the function $F(r)$ we get (39).

Now we will study the $N P V$ as a function of the two independent variables: the discount rate $r$ and the number $Q$ of units sold per year.

\section{Theorem 5}

(i) The $N P V$, as a function of the two independent variables $Q$ and $r$, is given by the following expression

$$
N P V(Q, r)=\left(p-C_{v}\right)\left(1-t_{e}\right) f(r)(Q-a)-I
$$

where the function $f=f(r)$ was defined in (4).

(ii) The $\operatorname{NPV}(Q, r)$ is a strictly increasing function of the variable $Q$ and a strictly decreasing function of the variable $r$ which has for the extreme values 0 and $+\infty$ of the variables $Q$ and $r$ respectively the following expressions:

$$
\begin{aligned}
& N P V(Q,+\infty)=\lim _{r \rightarrow+\infty} N P V(Q, r)=-I<0, \quad \forall Q>0, \\
& N P V\left(Q, 0^{+}\right)=\lim _{r \rightarrow 0^{+}} N P V(Q, r)=n\left(p-C_{v}\right)\left(1-t_{e}\right)\left(Q-Q_{c}\right), \quad \forall Q>0, \\
& N P V\left(0^{+}, r\right)=\lim _{Q \rightarrow 0^{+}} N P V(Q, r)=h(r), \quad \forall r>0, \\
& N P V(+\infty, r)=\lim _{Q \rightarrow+\infty} N P V(Q, r)=+\infty, \quad \forall r>0,
\end{aligned}
$$

where $Q_{c}$ is the accounting break-even point defined in (28), and $h=h(r)$ is the real function defined in (2).

(iii) The real function $h=h(r)$ has the following properties:

$$
h\left(0^{+}\right)=-\left(1-t_{e}\right) n\left(A+C_{f}\right)<0, h(+\infty)=-I<0,
$$

and it is a strictly increasing (decreasing) function when $A t_{e}<C_{f}\left(1-t_{e}\right)\left(A t_{e}>C_{f}\left(1-t_{e}\right)\right)$.

In the particular case in with $A t_{e}=C_{f}\left(1-t_{e}\right)$, then $h=h(r)$ is a constant function given by $h(r)=-I<0, \forall r>0$. 


\section{Proof.}

The properties follow from the previous results and elemenarty mathematical computations.

In particular, the partial derivatives of $N P V(Q, r)$ with respect to the variables $Q$ and $r$ are given by the following expressions:

$$
\begin{aligned}
& \frac{\partial N P V}{\partial Q}(Q, r)=\left(p-C_{v}\right)\left(1-t_{i g}\right) f(r)>0, \quad \forall Q, r>0, \\
& \frac{\partial N P V}{\partial r}(Q, r)=\left(p-C_{v}\right)\left(1-t_{i g}\right) Q f^{\prime}(r)<0, \quad \forall Q, r>0,
\end{aligned}
$$

and then the properties (i) and (ii) hold.

Therefore, the derivative of $h=h(r)$ is given by:

$$
h^{\prime}(r)=\left[C_{f}\left(1-t_{e}\right)-A t_{e}\right] \frac{G(r)}{r^{2}(1+r)^{n}}, \quad \forall r>0,
$$

where $G=G(r)$ was defined in (20). The sign of $h^{\prime}(r)$ depends of the sign of $\left[C_{f}\left(1-t_{e}\right)-A t_{e}\right]$, which will be positive (i.e. $h$ is a strictly increasing function of the variable $r$ ) when $A t_{e}<C_{f}\left(1-t_{e}\right)$ and so on. In the particular case $A t_{e}=C_{f}\left(1-t_{e}\right)$ we get that $h^{\prime}(r)=0, \forall r>0$, and then $h(r)$ is a constant given by $h(r)=-I, \forall r>0$.

\section{Remark 3}

In the Theorem 5 we showed that the increasing or decreasing behavior of the real function $h=h(r)$ depends on the sign of the expression

$C_{f}\left(1-t_{e}\right)-A t_{e}$,

which has a financial-accounting interpretation.

\section{Remark 4}

Owing to the properties (46) and (47) of the $N P V(Q, r)$, as a real function of the two independent variables $Q$ and $r$, and the expression (11) of the $N P V$ with parameters $I, n, p, C_{v}, A=I / n, C_{f}, t_{e}$, the zero curve of the $N P V=N P V(Q, r)$ is given by:

$$
\begin{aligned}
N P V(Q, r)=0 \Leftrightarrow & \left(p-C_{v}\right)\left(1-t_{i g}\right) f(r)(Q-a)=I \Leftrightarrow \\
& Q=a+\frac{I}{\left(p-C_{v}\right)\left(1-t_{i g}\right) f(r)}=a+\frac{b}{f(r)}=Q_{f}(r)
\end{aligned}
$$

and therefore, the zero curve of $N P V(Q, r)$ is given, in the plane $Q, r$, by the equation:

$Q=Q_{f}(r), \quad \forall r>0$,

or equivalently by

$r=Q_{f}^{-1}(Q), \quad Q>Q_{c}$,

where $Q_{f}(r)$ is the financial break-even point for the quantity $Q$ as a function of the discount rate $r$, defined by (12), and $Q_{f}{ }^{-1}$ is the inverse function of $Q_{f}$ which is defined $\forall Q>Q_{c}$, where $Q_{c}$ is the accounting breakeven point given by (28).

\subsection{Numerical results for an investment project}


We will consider the investment project with the following parameters (Brealey and Myers 1993):

- initial outlay: $I=150000(\$)$;

- $\quad$ explicit forecasted period of the project: $n=10$;

- annual amortization: $A=15000(\$)$;

- price per unit: $p=3.70$ (\$/unit);

- variable cost per unit: $C_{v}=3.00$ (\$/unit);

- annual fixed costs: $C_{f}=30000(\$)$;

- tax of earnings: $t_{e}=0.35$ (35\% annual);

- discount rate: $r=0.10$ (10\% annual);

Owing to the previous theoretical results we have:

$$
\begin{aligned}
& a=\frac{C_{f}-t_{e}\left(C_{f}+A\right)}{\left(p-C_{v}\right)\left(1-t_{e}\right)}=\frac{30000-0.35(30000+15000)}{(3.70-3) 0.65}=31318.68 \text { (Units) } \\
& b=\frac{I}{\left(p-C_{v}\right)\left(1-t_{e}\right)}=\frac{150000}{(3.70-3) 0.65}=329670,33 \text { (Units) } \\
& Q_{c}=\frac{C_{f}+A}{p-C_{v}}=a+\frac{b}{n}=\frac{30000+15000}{3.70-3}=\frac{45000}{0.70}=64285.71 \text { (Units) } \\
& t_{e} A-\left(1-t_{e}\right) C_{f}=-C_{f}+t_{e}\left(C_{f}+A\right)=-14250(\$) \\
& f=f(0.10)=\frac{1}{0.10}\left[1-\frac{1}{\left.(1.10)^{10}\right]=6.14}\right. \\
& h=h(0.10)=-I+f(0.10)\left[t_{e} A-\left(1-t_{e}\right) C_{f}\right]=-237560.08 \text { (\$) } \\
& m=m(r)=f(r)\left(p-C_{v}\right)\left(1-t_{i g}\right)=2.80(\$ / \text { Units) } \\
& Q_{f}=Q_{f}(0.10)=a+\frac{b}{f(0.10)}=-\frac{h(0.10)}{m(0.10)}=84971.01 \text { (Units) } \\
& N P V(Q)=h+m Q=2.80(Q-84971.01)(\$) .
\end{aligned}
$$

Taking into account the same parameters given before we can obtain the values of the financial break-even point $Q_{f}(r)$ as a function of the discount rate $r$ (see Table 1), and then we can get the graph of the real function $Q_{f}(r)$ vs $r$ (see Figure 1). Moreover, we can also plot the financial break-even point $y=Q_{f}(r)$ and the asymptotic straight line $y=a+b r$ as a function of the discount rate $r$ (see Figure 2).

Now we will perform a sensitivity analysis of the investment project in a neighboord of a reference point $r=0.10$ .We get the sensitivity analysis of the financial break-even point $Q_{f}(r)$ with respect to the price $p$, the annual fixed costs $C_{f}$ and the variable cost per unit $C_{v}$ as a function of the discount rate $r$. For that, we compute $Q_{f}(r)$ for the discount rate $r=0.11(+10 \%), r=0.12(+20 \%)$, and $r=0.09(-10 \%)$, and we compare the results with those for the reference discount rate $r=0.10$ (see Figure 3 ).

The sensitivity analysis of the financial break-even point $Q_{f}(r)$ suggests that price per unit $p$ lies on a more sensible point in comparison to the costs of any kind. If we look into the costs, it is seen that annual fixed costs $C_{f}$ is less sensible than variable costs per unit $C_{v}$ against the discount rate $r$

Figure 1: Graph of $Q_{f}(r)$ vs. $r$ 


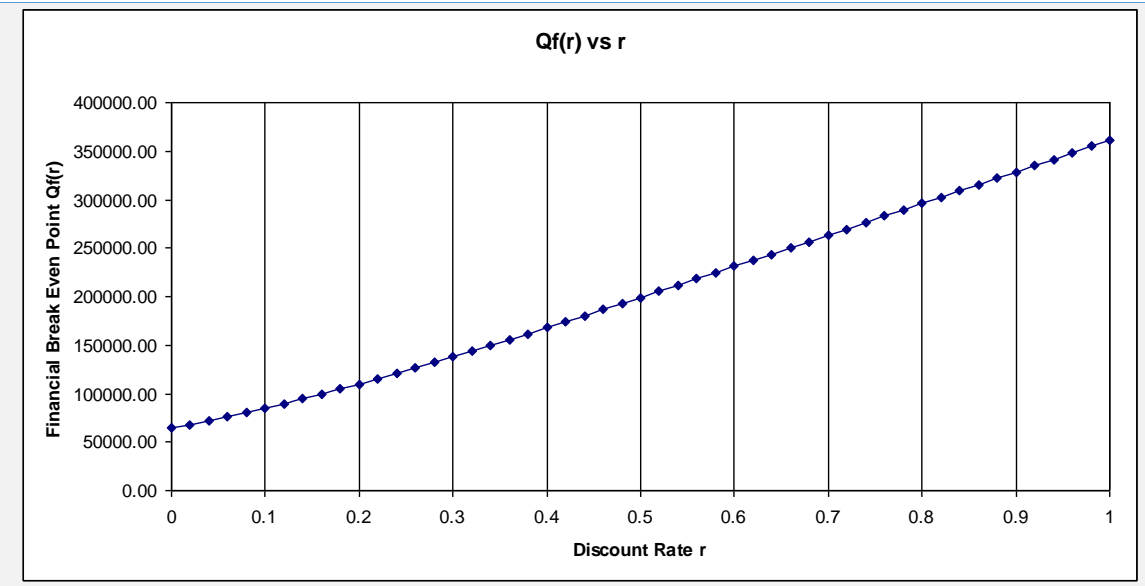

Table 1: Values of the financial break-even point $Q_{f}(r)$ vs the discount rate $r$

\begin{tabular}{|r|r|}
\hline Discount rate $\mathbf{r}$ & Financial break-even point $Q_{f}(r)$ \\
\hline 0.03 & 69966.10 \\
0.04 & 71964.05 \\
0.05 & 74012.50 \\
0.06 & 76110.32 \\
0.07 & 78256.32 \\
0.08 & 80449.28 \\
0.09 & 82687.94 \\
0.10 & 84971.01 \\
0.11 & 87297.17 \\
0.12 & 89665.11 \\
0.13 & 92073.48 \\
0.14 & 94520.95 \\
0.15 & 97006.17 \\
0.16 & 99527.83 \\
0.17 & 10208.59 \\
0.18 & 104675.16 \\
0.19 & 107298.23 \\
0.20 & 109952.56 \\
0.25 & 123650.30 \\
0.30 & 137954.98 \\
0.35 & 152742.30 \\
0.40 & 167908.96 \\
0.45 & 183371.28 \\
0.50 & 199062.79 \\
0.60 & 230936.39 \\
0.70 & 263238.31 \\
0.80 & 295795.68 \\
0.90 & 328506.70 \\
1.00 & 361311.27 \\
\hline & \\
\hline &
\end{tabular}

Figure 2: Graph of $Q_{f}(r)$ vs. $r$, and $y=a+b r$ vs. $r$ 


\section{Financial Break Even Point, Asymptotic Straight Line vs r}

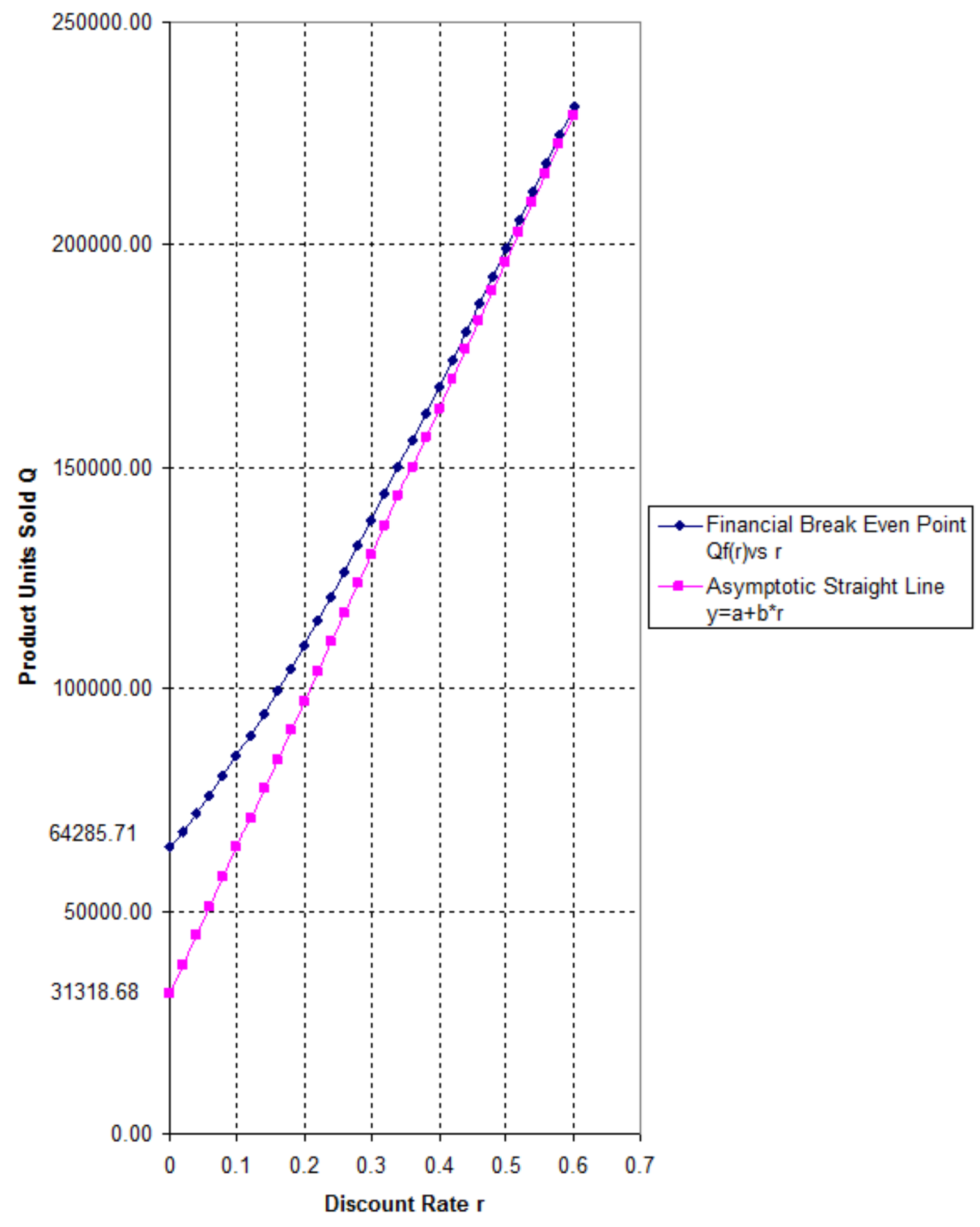


Figure 3: Sensitivity analysis of $Q_{f}$ with respect to $C_{v}, C_{f}$ and $p$

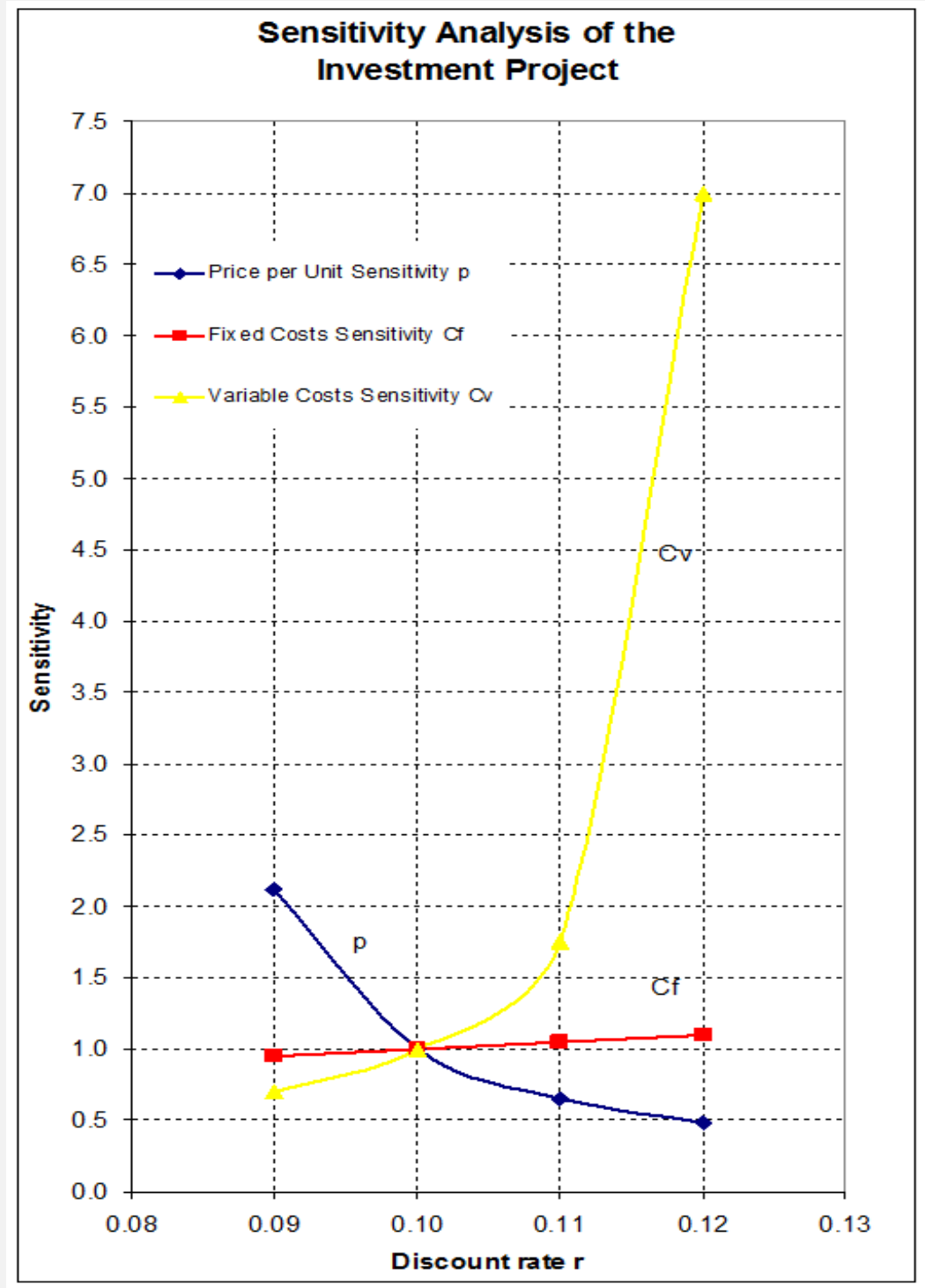

\subsection{Investment project with the independent variable $Q$ and an annual growth rate $g$}

We consider that the investment project defined in Section 2 has a constant annual growth rate $g>0$ in each year. In this case, we obtain the results given in the next theorem.

\section{Theorem 6}

The investment project, defined previously, with a annual growth rate $g>0$ has the following properties:

(i) The $N P V$, as a function of the three variables $Q, r$ and $g$, is given by:

$N P V(Q, r, g)=h(r)+m(r, g) Q$.

where

$m(r, g)=\left(p-C_{v}\right)\left(1-t_{e}\right) \Phi(r, g)>0$,

$\Phi(r, g)=\frac{1-\left(\frac{1+g}{1+r}\right)^{n}}{r-g}=\frac{1}{1+g} f\left(\frac{r-g}{1+g}\right)$, 
(ii) The financial break-even point $Q_{f}$ is given, as a function of the discount rate $r$ and the growing rate $g$, by the following expression:

$$
\begin{aligned}
Q_{f}(r, g)=\frac{I-\left(\left(1-t_{e}\right) C_{f}-t_{e} A\right) f(r)}{\left(\left(1-t_{e}\right) C_{f}-t_{e} A\right) f\left(\frac{r-g}{1+g}\right)} \frac{(1+g)}{\left(p-C_{v}\right)\left(1-t_{e}\right)} \\
=[b+a f(r)] \frac{1+g}{f\left(\frac{r-g}{1+g}\right)}=(1+g) F\left(\frac{r-g}{1+g}\right)\left(b+\frac{a}{F(r)}\right)
\end{aligned}
$$

where the real functions $f=f(r)$ and $F=F(r)$, and the coefficients $a$ and $b$ are given by the expressions (4), (13), (8) and (9) respectively.

(iii) The financial break-even point $Q_{f}=Q_{f}(r, g)$, given by (55), is a strictly increasing function of the discount rate $r$ and it has the following properties:

$Q_{f}\left(0^{+}, g\right)=\frac{n g}{(1+g)^{n}-1} Q_{c}<Q_{c}, Q_{f}(+\infty, g)=+\infty, \quad \forall g>0$,

$\frac{\partial Q_{f}}{\partial r}(r, g)>0, \quad \forall r>0, \quad \forall g>0$.

Moreover, for each $g>0$, the curve $y=Q_{f}(r, g) v s r$ has at $r=+\infty$ an asymptotic straight line given by the equation:

$y=a+b r$

which has a slope $b>0$ and y-intercept $a$, defined by (9) and (8) respectively. The asymptotic straight line is independent of the growth rate $g>0$ and coincides with the straight line for the particular case $g=0$.

Proof.

We follow the method developed in Section 2.

\subsection{Conclusions}

For a simple investment project an explicit expression of the corresponding net present value ( NPV ) as a function of the independent variable $Q$ in order to obtain a closed expression of the financial break-even point $Q_{f}$ (i.e. the value of $Q$ for which $N P V$ is zero) as a function of the parameters $I, n, C_{v}, C_{f}, t_{e}, r, p$ is derived. The behavior of $Q_{f}$ as a function of the discount rate $r$ is studied and it is proved that: (i) For $r$ negligible $Q_{f}$ equals the accounting break-even point $Q_{c}$ (i.e. the earnings before taxes (EBT) is null); (ii) When $r$ is large the graph of the function $Q_{f}=Q_{f}(r)$ has an asymptotic straight line with positive slope; (iii) From a sensitivity analysis we conclude that, while the influence of $p$ and $C_{v}$ on $Q_{f}$ is strong, the influence of $C_{f}$ on $Q_{f}$ is weak; (iv) Moreover, if we assume that the output grows at the annual rate $g$ the previous results still hold, and, of course, the graph of the function $Q_{f}=Q_{f}(r, g) v s r$ has, for all $g>0$, the same asymptotic straight line when $r \rightarrow \infty$ as in the particular case with $g=0$.

The paper provides the clear understanding, for a simple investment project, on the behavior of its financial breakeven point value as a function of the discount rate, and for our point of view our results are new in the economicalfinancial literature being the cornerstone of our proof the explicit expression of the net present value and the corresponding financial break-even point value. These results can be taken into account for investment projects, especially in countries with very small or very large discount rates. 


\section{Acknowledgements}

The present work has been presented at the World Finance Conference, Buenos Aires, $22-24$ July 2015, and it has been sponsored by the Projects PIP № 0534 from CONICET-Universidad Austral. The authors is grateful to anonymous reviewers for valuable comments to improve the paper.

\section{References}

Alhabeeh MJ, (2012). Mathematical finance. Hoboken, New Jersey: Wiley. http://dx.doi.org/10.1002/9781118106907

Baker R., Fox R., (2003). Capital investment appraisal: A new risk premium model. International Transactions on Operations Research, 10: 115-126. http://dx.doi.org/10.1111/1475-3995.00398

Beaves R.G., (1988). Net present value and rate of return: implicit and explicit reinvestment assumptions. The Engi-neering Economist, 33: 275-302. http://dx.doi.org/10.1080/00137918808966958

Bierman JH, Smidt S, (1993). The capital budgeting decision. New York: Macmillan.

Bodmer E, (2015). Corporate and project finance modeling: Theory and practice. Hoboken, New Jersey: Wiley.

Brick I.E., Weaver D.G., (1997). Calculating the cost of capital of an unlevered firm for use in project evaluation. Review of Quantitative Finance and Accounting, 9: 111-129. http://dx.doi.org/10.1023/A:1008213708206

Brealey R, Myers S, (1993). Fundamentos de financiación empresarial. Madrid: Mc Graw- Hill.

Chung, K.J. and Lin, S.D. (1998) An exact solution of cash flow for an integrated evaluation of investment in invento-ry and credit. Production Planinning \& Control, 9, 360-365. http://dx.doi.org/10.1080/095372898234082

De Pablo A, Ferruz L, Santamaria R, (1990). Análisis práctico de decisiones de inversión y financiación en la empresa. Barcelona: Ariel.

Fernandez B. M, (1991). Dirección financiera de la empresa. Madrid: Pirámide.

Gokiene R., (2010). Marginal break even between maintenance strategies alternatives. Engineering Economics, 21 (2): 136-141.

Grinyer J.R., Walker M., (1990). Deprival value-based accounting rates of return under uncertainty. A note. Econom-ical Journal, September: 918-922.

Hajdasinski M.M., (1993). The payback period as a measure of profitability and liquidity. The Engineering Economist, 38: 177-191. http://dx.doi.org/10.1080/00137919308903096

Hajdasinski M.M., (1995). Remarks in the context of the case for a generalized net present value formula. The Engineering Economist, 40: 201-210. http://dx.doi.org/10.1080/00137919508903144

Hajdasinski M.M., (1996). Adjusting the modified internal rates of return. The Engineering Economist, 41: 173186. http://dx.doi.org/10.1080/00137919608967484

Hajdasinski M.M., (1997). NPV- Compatibility, project ranking, and related issues. The Engineering Economist, 42: 325-339. http://dx.doi.org/10.1080/00137919708903186

Hajdasinski M.M., (2004). Technical note- the internal rate of return (IRR) as a financial indicator. The Engineering Economist, 49: 185-197. http://dx.doi.org/10.1080/00137910490453437

Hartman J.C., (2000). On the equivalence of net present value and market value added as measures of a project's economic worth. The Engineering Economist, 45: 158-165. http://dx.doi.org/10.1080/00137910008967543

Hartman J.C., Schafrick I.C., (2004). The relevant internal rate of return. The Engineering Economist, 49: 139-158. http://dx.doi.org/10.1080/00137910490453419

Hazen G.B., (2003). A new perspective on multiple internal rates of return. The Engineering Economist, 48: 31-51. http://dx.doi.org/10.1080/00137910308965050

Kim J.S., Kim J.W., (1996). A breakeven procedure for a multi-period project. The Engineering Economist, 41: 95104. http://dx.doi.org/10.1080/00137919608967480

Kim Y.H., Chung K.H., (1990). An integrated evaluation of investment in inventory and credit: A cash flow approach. Journal of Business Finance \& Accounting, 17: 381-390. http://dx.doi.org/10.1111/j.14685957.1990.tb01192.x

Lan S.P., Chung K.J., Chu P., Kuo P.F., (2003). The formula approximation for the optimalycletime of the net present value. The Engineering Economist, 48: 79-91. http://dx.doi.org/10.1080/00137910308965053

Lohmann J.R., (1994). A clarification of the concepts of income, wealth base, and rates of return implications of alternative project evaluation criteria. The Engineering Economist, 39: 355-361. http://dx.doi.org/10.1080/00137919408903134

Lohmann J.R., Baksh S.N., (1993). The IRR, NPV and payback period and their relative performance in common capi-tal budgeting decision procedures for dealing with risk. The Engineering Economist, 39: 17-47. http://dx.doi.org/10.1080/00137919308903111

López D. G, (2003). Finanzas corporativas. Buenos Aires: Grupo Guía. 
Machain L, (2002). El valor actual neto como criterio óptimo para seleccionar alternativas de inversión. Trabajo Final, Especialidad en Finanzas. Univ. Nacional de Rosario.

Martinez Medina I., Val Arreola D., Tzintzun Rascón R., Conejo Nava J.J., Tena Martinez M.J., (2015). Private competi-tiveness, production costs and break-even analysis of representative pork production units. Revista Mexicana de Ciencias Pecuarias, 6 (2): 193-205.

Moon I., Yun W., (1993). A note in evaluating investments in inventory systems: a net present value framework. The Engineering Economist, 39: 93-99. http://dx.doi.org/10.1080/00137919308903115

Nykamp S., Bakker V., Molderink A., Hurink J.L., Smit, G.J.M., (2014). Break-even analysis for the storage of PV in power distribution grids. International Journal of Energy Research, 38: 1112-1128. http://dx.doi.org/10.1002/er.3106

Paek J.H., (2000). Running a profitable construction company: Revisited break-even analysis. Journal of Management in Engineering, May-June: 40-46. http://dx.doi.org/10.1061/(ASCE)0742-597X(2000)16:3(40)

Pasin F., Leblanc D., (1996). A simple method for calculating the rate for an investment project. The Engineering Economist, 41: 365-368. http://dx.doi.org/10.1080/00137919608967501

Pierru A., Feuillet-Midrier E., (2002). Discount rate value and cash flow definition: a new relationship and its implications. The Engineering Economist, 47: 60-74. http://dx.doi.org/10.1080/00137910208965023

Prakash A.J., Dandapani K., Karels G.V., (1988). Simple resource allocation rules. Journal of Business Finance \& Accounting, 15: 447-452. http://dx.doi.org/10.1111/j.1468-5957.1988.tb00147.x

Reichelstein S., (2000). Providing managerial incentives: Cash flows versus accrual accounting. Journal of Account-ing Research, 38: 243-269. http://dx.doi.org/10.2307/2672933

Roumi E., Schnabel J.A., (1990). Evaluating investment in inventory policy: a net preset value framework. The Engi-neering Economist, 35: 239-246. http://dx.doi.org/10.1080/00137919008903020

Sapag C. N., (2001). Evaluación de proyectos de inversión en la empresa. México: Prentice Hall.

Sarkar C.R., Sarkar A., (2013). Capital Structure, leverage and financing decision: An empirical analysis of selected public sector oil and gas companies in India. The Journal of Institute of Public Enterprise, 36: 89-103.

Schwindt C., Zimmermann J., (2001). A steepest ascent approach to maximizing the net present value of projects. Mathematical Methods of Operations Research, 53: 435-450. http://dx.doi.org/10.1007/s001860100129

Shull D.M., (1992). Efficient capital project selection through a yield-based capital budgeting technique. The Engineering Economist, 38: 1-18. http://dx.doi.org/10.1080/00137919208903083

Shrieves R.E., Wachowicz J.M. Jr., (2001). Free cash flow (FCF), economic value added (EVA), and net present value (NPV): A reconciliation of variations of discounted-cash-flow (DCF) valuation. The Engineering Economist, 46: 33-52. http://dx.doi.org/10.1080/00137910108967561

Stanford R.E., (1989). Optimizing profits from a system of accounts receivable. Management Science, 35 : 1227 1235. http://dx.doi.org/10.1287/mnsc.35.10.1227

Suarez Suarez AS, (1991). Decisiones óptimas de inversión y financiación en la empresa. Madrid: Ediciones Pirámi-de.

Suciu G., (2010). Risk diagnosis in the context of economic crisis. Bulletin of the Transilvania University of Brasov. Series V: Economic Sciences, 3 (52): 321-326.

Tang S.L., Tang H.J., (2003). The variable financial indicador IRR and the constant economic indicador NPV. The Engineering Economist, 48: 69-78. http://dx.doi.org/10.1080/00137910308965052

Vanhoucke M., Demeulemeester E., Herroelen W., (2001a). On maximizing the net present value of a project under renewablee resource constraints. Management Science, 47: 1113-1121. http://dx.doi.org/10.1287/mnsc.47.8.1113.10226

Vanhoucke M., Demeulemeester E., Herroelen W., (2001b). Maximizing the net present value of a project with linear time-dependent cash flow. International Journal of Production Research, 39 (14): 3159-3181. http://dx.doi.org/10.1080/00207540110056919

Villalobos JL, (2001). Matemáticas financieras. México: Prentice Hall.

Yang J.G.S., Meziani A.S., (2012). Break-even point between short-term and long-term capital gain (loss) strategies. The Journal of Investing, Winter: 115-126.

Zhang D., (2005). A different perspective in using multiple internal rates of return: the IRR parity technique. The Engineering Economist, 50: 327-335. http://dx.doi.org/10.1080/00137910500348376 